\title{
$\prod_{\text {mats }}$ de participação social
}

\author{
Viviane Cristina Pinto \\ Cayo Honorato ${ }^{2}$
}

1 Pesquisadora do grupo Terra em Cena: teatro, audiovisual e educação do campo, vinculado ao curso de Educação do Campo da Faculdade UnB Planaltina (FUP). Mestre em Estudos Culturais pela Escola de Artes Ciências e Humanidades, da Universidade de São Paulo (USP). Foi consultora pela Unesco para a Secretaria Nacional de Juventude para o desenvolvimento de atividades culturais no processo da $3^{\mathrm{a}}$ Conferência Nacional de Juventude. E-mail: <vivianecrispinto@gmail.com>

2 Professor adjunto no Departamento de Artes Visuais (VIS) da Universidade de Brasília (UnB), na área de História e Teoria da Educação em Artes Visuais, com pesquisa sobre a atuação dos públicos e a mediação cultural e sobre as relações entre arte, educação e política. Doutor em Educação pela Faculdade de Educação, da USP. Integra a rede Another Roadmap for Arts Education desde 2015. É pesquisador associado do Centre for the Study of the Networked Image (CSNI) da London South Bank University (LSBU), Reino Unido, desde 2018, onde atualmente desenvolve pesquisa de pós-doutorado. E-mail: <cayohonorato.unb@gmail.com> 


\section{Resumo:}

Este artigo aborda reflexivamente a experiência da Manifesta, mostra cultural da $3^{\text {a }}$ Conferência Nacional de Juventude (2015), que procurou reconhecer e valorizar o que os jovens estavam produzindo em termos de práticas culturais e conhecimentos científicos. O método adotado para o desenvolvimento da mostra buscou ampliar e aprofundar a participação da juventude brasileira no processo democrático. No atual contexto de ruptura com as conquistas democráticas, em que tal experiência não está mais no horizonte de possibilidades, parece-nos fundamental refletir sobre o que podemos aprender com ela. Para tanto, apresentamos as ideias norteadoras da Manifesta, sua metodologia e etapas de desenvolvimento, os desafios de sua organização, assim como alguns de seus desdobramentos.

Palavras-chaves: Manifesta. Mostra cultural. $3^{\text {a }}$ Conferência Nacional de Juventude. Participação social.

\section{Abstract:}

This article discusses the experience of Manifesta, the cultural festival of the 3rd Brazilian Youth Conference (2015), created to recognize and value what young people were producing in terms of cultural practices and scientific knowledge in Brazil. The method adopted for the development of the festival sought to broaden and deepen the participation of the Brazilian youth in the democratic process. In the current context where democratic achievements have been attacked - and in which such experience is no longer on the horizon -, we believe that it is fundamental to reflect on what we can learn from it. For such, we present Manifesta's guiding ideas, its methodology and development stages, the challenges of its organization, and some of its outcomes.

Keywords: Manifesta. Cultural festival. $3^{\text {a }}$ Conferência Nacional de Juventude. Social participation. 


\section{INTRODUÇÃO}

Todo ser humano tem o direito de fazer parte no governo do seu país diretamente ou por intermédio de representantes livremente escolhidos. (ONU, 2009, p. 11)

Todo o poder emana do povo, que o exerce por meio de representantes eleitos ou diretamente, nos termos desta Constituição.(BRASIL, 1988)

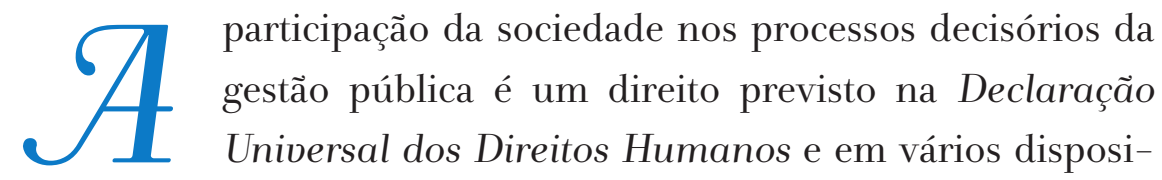
tivos da Constituição Federal brasileira. ${ }^{3}$ Ao governo cabe difundir e promover tal participação, bem como fortalecer os mecanismos democráticos que permitem a interação entre o Estado e a sociedade para o desenvolvimento de políticas públicas condizentes com as necessidades concretas da população. Entretanto, por princípio, formas conservadoras e autoritárias de pensar a atuação do Estado

3 Em sintonia com o objeto deste artigo, referimo-nos ao parágrafo primeiro do Art. 216-A, que trata do Sistema Nacional de Cultura, registrando em seu inciso $X$ o princípio da "democratização dos processos decisórios com participação e controle social"; assim como ao parágrafo oitavo do Art. 227, que integra o Capítulo VII sobre a Família, a Criança, o Adolescente, o Jovem e o Idoso, garantindo que a lei estabelecerá "o estatuto da juventude, destinado a regular os direitos dos jovens". (BRASIL, 1988) Por sua vez, o Estatuto da Juventude prevê princípios, diretrizes e inúmeros dispositivos que valorizam e garantem a participação social da juventude brasileira (vide Lei n 12.852, de 5 de agosto de 2013). 
desencorajam a participação popular e a compreensão das relações de poder na esfera política.

Nos últimos anos, testemunhamos a ascensão de um conservadorismo (CHAUI, 2016) em detrimento das conquistas democráticas que, visando garantir o exercício da cidadania, favorecem o diálogo e a participação social. Se já havia muitos desafios a serem enfrentados para garantir a efetividade das políticas públicas e dos mecanismos de participação popular, agora nos deparamos com outro contexto, de retrocesso e ataque às conquistas democráticas, vide o pronunciamento público do presidente Bolsonaro na posse do segundo Ministro da Educação em menos de cem dias de governo:

[...] nós queremos uma garotada que comece a năo se interessar por política como é [sic] atualmente dentro das escolas, mas comece realmente a aprender coisas que [referindo-se ao Ministro da Ciência e Tecnologia presente na cerimônia] possa [sic] levar, quem sabe, ao espaço, no futuro. (MAZUI, 2019, grifo nosso)

A ascensão da extrema direita ao poder afeta diretamente os alicerces de nossa frágil democracia. Os efeitos podem ser percebidos no desmantelamento estrutural das políticas públicas, em especial as de cultura e educação. Isso pôde ser notado logo nos primeiros dias do governo Bolsonaro, quando foi publicada a Medida Provisória $n^{\circ}$ 870/2019, que extinguiu o Ministério da Cultura, transformando-o em Secretaria Especial do Ministério da Cidadania. Ou ainda, no corte de cerca de $25 \%$ da verba para gastos discricionários (despesas não obrigatórias por lei, como investimentos e despesas em geral, tais como contas de luz e água, bolsas acadêmicas, compra de equipamentos, entre outras) das universidades e institutos federais de ensino. Nesse contexto, a crise econômica serve de oportunidade para o desmonte das políticas públicas, tal como exposto por Naomi Klein (2008) em seu livro A doutrina do choque: a ascensão do capitalismo de desastre. 
Assim, no ano em que deveria ocorrer a $4^{\text {a }}$ Conferência Nacional de Juventude, ${ }^{4}$ nossa hipótese é que a Manifesta, mostra cultural da $3{ }^{\text {a }}$ Conferência Nacional de Juventude, tem sua relevância na forma inovadora com que buscou ampliar e aprofundar a participação da juventude brasileira no processo democrático. Desse modo, pretendemos refletir sobre o que se pode aprender com essa experiência.

O processo da $3^{\text {a }}$ Conferência Nacional de Juventude $\left(3^{a} \mathrm{CNJ}\right)$ teve início em maio de 2015 e culminou na etapa nacional em Brasília, de 16 a 19 de dezembro de 2015, contando com a presença de mais de 3 mil pessoas de todo o país, entre delegados, proponentes de atividades culturais, convidados internacionais, observadores e envolvidos na organização. Com o tema "As várias formas de mudar o Brasil", a $3{ }^{\text {a }}$ CNJ teve como objetivos principais: atualizar a agenda da juventude para o desenvolvimento do país; reconhecer e potencializar as múltiplas formas de expressão juvenil; combater todas as formas de preconceito; e fortalecer os direitos dos jovens, como previsto no Estatuto da Juventude.

As Conferências de Juventude foram realizadas em nível municipal, regional, estadual e nacional, com objetivo de debater as diretrizes das políticas públicas de juventude a serem implementadas pelos governos nos diferentes níveis da federação. Esse processo de participação da juventude na definição das prioridades das políticas públicas serve para que sejam desenvolvidas ações em sintonia com a realidade concreta vivenciada pelos jovens.

Considerando "as novas formas de organização juvenil e a interação da sociedade, cada vez mais conectada com as novas tecnologias" (UNESCO, 2015, p. 4), uma importante inovação metodológica da $3^{\mathrm{a}}$ CNJ foi a participação dos jovens por meio de uma plataforma

4 Conforme o Estatuto da Juventude, Capítulo II, Artigo 41, inciso V, compete à União "convocar e realizar, em conjunto com o Conselho Nacional de Juventude, as Conferências Nacionais de Juventude, com intervalo máximo de 4 (quatro) anos". (BRASIL, 2013) 
digital, com a elaboração de 305 propostas e a eleição de 484 delegados para a etapa nacional. Outra inovação metodológica para ampliar a participação da juventude no processo democrático foi o desenvolvimento da Manifesta, a mostra cultural da $3^{\text {a }} \mathrm{CNJ}$, objeto deste artigo.

A Manifesta teve como objetivo central valorizar o potencial criativo da juventude, estimulando situações de interação entre os participantes da $3^{\mathrm{a}} \mathrm{CNJ}$. Através de uma Chamada Pública de amplitude nacional, mais de 870 jovens se inscreveram para participar da mostra. Ao longo da $3^{\text {a }} \mathrm{CNJ}$ foram apresentadas 83 atividades em múltiplas formas de expressão e campos do conhecimento. A seguir, apresentamos as ideias norteadoras da Manifesta, sua metodologia de trabalho e etapas de desenvolvimento, bem como o balanço dos desafios de sua organização e alguns de seus desdobramentos.

\section{Cultura e democracia: IDelas norteadoras}

'Democracia' é um conceito em disputa.

(MIGUEL, 2016, p. 29)

Em uma democracia pode-se estabelecer formas significativas de atuação do Estado, ao desenvolver mecanismos de gestão compartilhada - tais como audiências públicas, conselhos, sistemas, planos e conferências nacionais - para a construção de políticas públicas que considerem a participação ativa e conjunta da sociedade civil e dos entes da federação.

As práticas democráticas participativas têm como princípios: o diálogo, entendendo-o enquanto um interesse efetivo no encontro entre sujeitos que compartilham seu pensar e agir; e a tomada de decisões coletivas em relação às prioridades das políticas públicas. Para garantir o exercício da cidadania e a efetividade desses princípios, é fundamental que os processos participativos organizem estratégias que reconheçam a expressão e a riqueza dos diversos pontos de vista dos indivíduos participantes. 
A prática da gestão compartilhada com a participação da sociedade na decisão das políticas públicas é recente na realidade social brasileira, tendo se estruturado na década de 2000. Entretanto, existem muitos desafios a serem enfrentados para garantir a efetividade das políticas públicas e dos mecanismos de participação social (AVRITZER, 2011; SZWAKO, 2012), garantindo, por sua vez, a efetividade das pautas levantadas, debatidas e consensuadas nos inúmeros processos institucionais de participação social, ou ainda, respondendo às novas e diversas formas de organização política da sociedade, aos novos agentes e demandas insurgentes diante da crise da "democracia representativa elitista". (SANTOS; AVRITZER, 2005)

A Manifesta parte de um entendimento de "cultura" em sentido amplo, tal como desenvolvido pelos Estudos Culturais, que a fortaleceram para o uso democrático. Dessa perspectiva, a cultura é entendida como a capacidade de desenvolvimento comum a todos os indivíduos, tanto no domínio das artes, das ideias e do conhecimento, quanto no âmbito das práticas sociais. Do mesmo modo, a cultura pode ser compreendida como um potencial de transformação da sociedade, com capacidade de evidenciar os conflitos, contradições e desigualdades históricas de nossa formação social. Nesse sentido, as ações culturais do Estado devem reconhecer e apoiar a produção, a difusão e a fruição simbólica da sociedade na sua diversidade. (WILLIAMS, 1989, 2011)

Com a Mostra Cultural, pretendeu-se pensar o desenvolvimento da dimensão cultural integrado à dimensão política no sentido de qualificar a esfera de participação social da $3^{\mathrm{a}} \mathrm{CNJ}$. Mas como juntar política e cultura no processo das conferências? Ao invés de seguir o senso comum de pensar a promoção de atividades culturais "para" jovens, foi fundamental saber, reconhecer e valorizar o que os

5 A 1a Conferência Nacional de Educação, Cultura e Desporto foi realizada em 24 de novembro de 2000; a 1a Conferência Nacional de Cultura foi realizada em 2005; a 1a Conferência Nacional de Juventude foi realizada em 2008. 
jovens estão desenvolvendo de produções simbólicas e de conhecimentos que expressam suas experiências de vida. Essa escolha tem sua razão de ser no movimento de ampliar e aprofundar a participação da juventude no processo democrático, bem como na expectativa de que a $3^{\text {a }} \mathrm{CNJ}$ pudesse ser capaz de reconhecer e potencializar as várias formas de expressão dos jovens. Nesse exercício de pensar e agir surge a Manifesta, um espaço de reconhecimento público das manifestações culturais dos jovens que procurou promover a comunicação e o encontro, estimulando situações de interação entre os participantes da $3^{\mathrm{a}} \mathrm{CNJ}$.

\section{MÉTOdO}

Enquanto instituições organizadoras, o Conselho Nacional de Juventude (Conjuve) e a Secretaria Nacional de Juventude (SNJ) publicizaram a Resolução $n^{\circ}$ 8/2015 para regulamentar o desenvolvimento de atividades culturais no processo da $3^{\mathrm{a}} \mathrm{CNJ}$, bem como a Chamada Pública $n^{\circ} 1 / 2015$ SNJ/SG/PR para a inscrição e a seleção de atividades culturais para compor a programação da etapa nacional da $3^{\text {a }} \mathrm{CNJ}$.

A Resolução $n^{\circ}$ 8/2015 previa as seguintes etapas de desenvolvimento da Manifesta: etapa Inspiração, de compartilhamento de ideias e informações para o desenvolvimento de atividades artísticas, científicas, culturais e de comunicação no processo da $3^{\text {a }} \mathrm{CNJ}$; etapa Chamada Pública, de desenvolvimento e comunicação da chamada pública para a seleção de atividades para compor a programação da etapa nacional da $3^{\mathrm{a}} \mathrm{CNJ}$; etapa Seleção, de habilitação, seleção e curadoria das propostas de atividades inscritas; etapa Divulgação, de publicização das atividades selecionadas para a etapa nacional da $3^{\text {a }} \mathrm{CNJ}$; etapa Nacional, de realização da programação das atividades culturais selecionadas para a Manifesta. (BRASIL, 2015d)

Na primeira etapa, a estratégia se concentrou na comunicação de conteúdos sobre a mostra: o que é, quem organiza, quais são as fases 
de desenvolvimento e como participar. Tais informações foram publicizadas no site da $3^{\text {a }}$ CNJ e organizadas em material impresso para as Comissões Organizadoras Estaduais (COEs). Além disso, a proposta da mostra foi apresentada para representantes das COEs, em um momento de formação realizado no dia 7 de agosto de 2015, no Palácio do Planalto, em Brasília, contando com transmissão ao vivo pelo Portal da Juventude. (3 ${ }^{a}$ CONFERÊNCIA..., [2019])

A Chamada Pública especificou o público destinatário, as condições de participação, a forma de inscrição, o processo e os critérios de seleção para a mostra cultural da $3^{\mathrm{a}} \mathrm{CNJ}$. O público destinatário foi pessoas físicas (produtores, artistas, pesquisadores, agentes culturais, entre outros), na faixa etária jovem, de 15 a 29 anos de idade. As atividades propostas poderiam ser individuais ou coletivas e as atividades coletivas poderiam ter, entre os proponentes, participantes de outras faixas etárias, devendo, necessariamente, especificar no ato da inscrição como se verificava o protagonismo dos jovens. A inscrição das atividades foi gratuita, pelo site da $3^{\mathrm{a}} \mathrm{CNJ}$, durante o período de 14 de setembro de 2015 a 18 de outubro de 2015. (BRASIL, 2015b)

Pelas condições de participação definidas na Chamada, seriam custeadas passagem, hospedagem e alimentação para até 250 proponentes de atividades culturais. Uma Comissão de especialistas - com pesquisa e atuação no campo cultural e sensível à temática da juventude - ficou responsável pela análise dos conteúdos das atividades inscritas, devendo garantir a diversidade de linguagens, de formas de expressão e áreas do conhecimento. ${ }^{6}$ As pro-

6 A Comissão foi composta por especialistas da rede de contatos da SNJ, representantes governamentais, de organizações internacionais e da sociedade civil, tais como: Ministério da Cultura (MinC), Ministério da Educação (MEC), Instituto de Pesquisa Econômica Aplicada (Ipea), Fundo de Populações das Nações Unidas (UNFPA), Programa Conjunto das Nações Unidas sobre HIV/AIDS (Unaids), Fundo das Nações Unidas para a Infância (Unicef), Organização das Nações Unidas para a educação, a ciência e a cultura (Unesco), Ação Educativa, Universidade Estadual do Ceará (UECE), Movimento dos Trabalhadores Rurais Sem Terra (MST) e pelo Conjuve. 
postas foram avaliadas quanto à sua criatividade, qualidade, objetividade na apresentação e quanto ao seu impacto e relevância no contexto dos objetivos da $3^{\text {a }}$ CNJ. Também foram critérios de avaliação a abertura da proposta do proponente para a interação e participação do público da $3^{\mathrm{a}} \mathrm{CNJ}$ e a participação do proponente em uma das diversas etapas da Conferência de Juventude. ${ }^{?}$

A divulgação da Chamada, bem como das atividades selecionadas, foi realizada pelas redes sociais da SNJ, pelo site da $3^{\text {a }} \mathrm{CNJ}$ e pelo Portal da Juventude. A análise das estratégias de comunicação da $3^{\text {a }}$ CNJ mostrou que os materiais de divulgação da Manifesta (cards para redes sociais) tiveram recordes de compartilhamentos e de perfis alcançados na página de Facebook da SNJ em relação às outras divulgações, evidenciando o interesse no assunto e a importância do investimento nesses meios de comunicação.

Para garantir o fomento de atividades em múltiplas linguagens e formas de expressão, a Mostra se organizou nos seguintes espaços: Projeções, adequado para exibições audiovisuais; Apresentações, adequado para apresentações musicais e das artes cênicas; Instalações, próprios para intervenções das artes visuais, experimentos científicos, dentre outras atividades; Vivências e reflexões, adequados para atividades discursivas em diversas linguagens, campos do conhecimento e formas de expressão; e Comunicações, adequados para atividades de comunicação popular, colaborativas, independentes, de cultura digital e mídia livre.

A infraestrutura e logística para a realização do evento como um todo - inclusive para os espaços da mostra, bem como hospedagem, alimentação e traslado dos seus participantes - foi viabilizada por meio de contrato com uma empresa de eventos licitada pela Secretaria-Geral da Presidência da República. ${ }^{8}$ Já as passagens

7 Como disposto no Regimento, a $3^{\text {a }} \mathrm{CNJ}$ contou com as seguintes etapas: Etapas livres e territoriais; Etapas das juventudes de povos e comunidades tradicionais; Etapas municipais e regionais; Etapas estaduais e do Distrito Federal; e a Etapa digital.

8 A SNJ estava ligada à Secretaria-Geral da Presidência da República até a instituição de uma Reforma Administrativa, por meio da Medida Provisória n 696, de 2 de outubro de 2015, 
deveriam ser emitidas pelos servidores da SNJ diretamente pelo sistema de emissão de passagens da administração pública federal. Para garantir a realização das atividades, a Mostra contou com uma equipe de mediadores dos espaços e das intervenções, composta por sete participantes da comissão de avaliação e seleção das propostas e por sete produtores locais.

O método adotado para a realização da Chamada Pública de amplitude nacional garantiu que todo e qualquer jovem brasileiro pudesse propor atividades culturais para a programação da $3^{\text {a }}$ CNJ. Mais de 870 jovens inscreveram 328 atividades individuais e coletivas. Esse número é relevante, considerando que houve apenas um mês de divulgação e período de inscrição. A seguir, apresentamos alguns dados consolidados das inscrições na Manifesta por estado, gênero, autodeclaração do proponente da atividade em relação à raça/etnia, assim como pela categoria da atividade proposta (se eram científicas, artístico-culturais ou de comunicação). Vale ressaltar que o estado da Bahia despontou com o maior número de inscrições, ultrapassando o eixo Rio-São Paulo, que tradicionalmente concentra as propostas de ações culturais. O resultado reflete a mobilização conseguida com as etapas municipais e regionais na Bahia. Além disso, a quantidade de proponentes mulheres $(40,4 \%)$ e a maioria de proponentes que se autodeclarou como preta e parda $(67,6 \%)$ é relevante, considerando o predomínio histórico de homens brancos como proponentes de ações culturais.

quando passou a integrar a Secretaria de Governo da Presidência da República, até ser instituída a Estrutura Regimental do Ministério, que passou suas atribuições para o então Ministério das Mulheres, da Igualdade Racial e dos Direitos Humanos. Através do decreto $n^{\circ}$ 9.673, de 2 de janeiro de 2019, a SNJ passou a integrar a estrutura do Ministério da Mulher, da Família e dos Direitos Humanos. 
Gráfico I: inscrições na Manifesta por estado.

\section{INCRIÇ̃̃ES}

\section{ESTADOS}

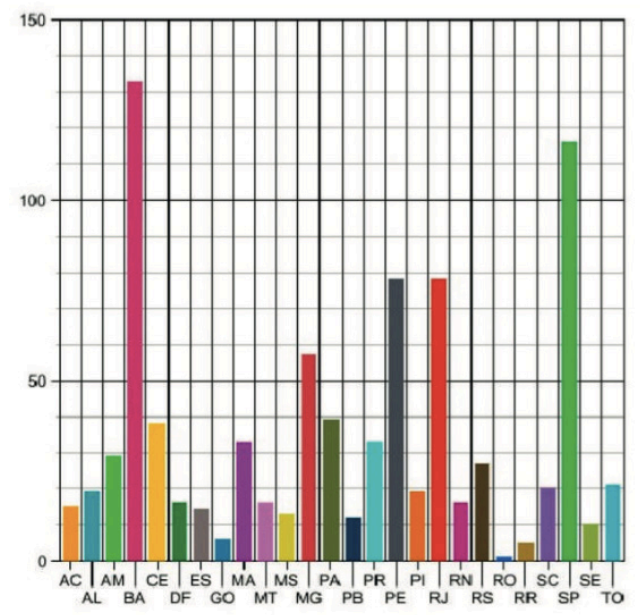

\section{CADASTROS:}

BA- 133 AC - 15

SP - 116 ES - 14

PE - 78 MS - 13

RJ - 78 PB - 12

MG - 57 SE - 10

PA - 39 GO - 6

CE - 38 RR - 5

MA - 33 RO - 1

PR - 33

AM - 29

RS - 27

TO - 21

SC - 20

AL - 19

PI - 19

MT - 16

DF - 16

RN - 16

Gráfico Il: inscrições em relação à autodeclaração dos proponentes em termos de raça/etnia.

\section{INCRIÇÕES}

\section{COMO SE AUTO DECLARA?}

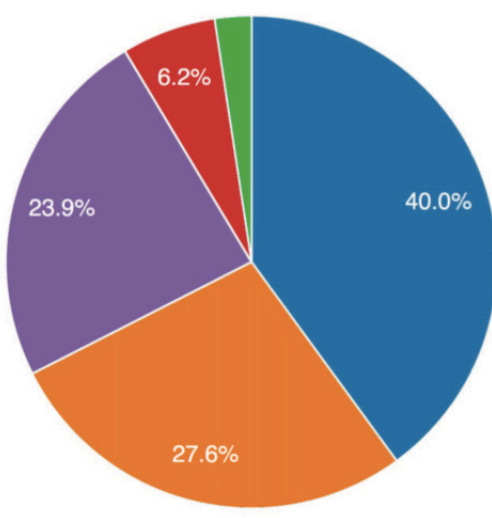

CADASTROS:

PRETO - 348

PARDO - 240

BRANCO - 208

INDÍGENA - 54

AMARELO - 21 


\section{INCRIÇÕES}

\section{CLASSIFICAÇÃO DA ATIVIDADE}

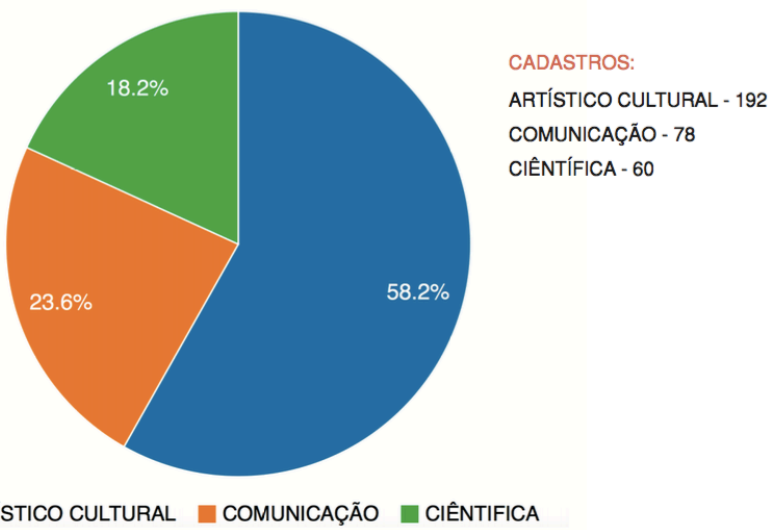

aRTÍSTICO CULTURAL — COMUNICAÇÃO @ CIÊNTIFICA

Acreditamos que a quantidade expressiva de atividades de comunicação resulta do estímulo à cobertura colaborativa no processo da $3^{\text {a }} \mathrm{CNJ}$, a partir da realização do Encontro de Midialivrismo e Juventude, que aconteceu no Rio de Janeiro, em maio de 2015. O evento reuniu duzentos produtores independentes de conteúdo e impulsionou os jovens a registrar, publicar e compartilhar conteúdos sobre as conferências.

A partir da Chamada Pública foram selecionadas 93 atividades protagonizadas por cerca de 250 jovens. Ao longo da $3^{\text {a }} \mathrm{CNJ}$ foram apresentadas 83 atividades em múltiplas formas de expressão: teatro, dança, música, artes visuais, cinema, performance, artes integradas, grafite, hip-hop, poesia, circo, cultura popular, indígena, cigana, pesquisas científicas, atividades de comunicação independente, mídia livre e cultura digital. Registramos aqui algumas dessas atividades: (1) "Palavras ancestrais: imprensa negra na luta por direitos no Brasil", realizada no espaço Comunicações e que se propôs a debater "o papel histórico das organizaçōes negras e a produção de uma mídia alternativa comprometida com a defesa da democracia e com a construção de uma nação justa e igualitária"; (2) "Sistemas de Cultura em diálogo: por um protagonismo jovem 
no processo de institucionalização das políticas culturais", realizada por jovens mulheres do estado da Bahia, no espaço Vivências e Reflexões, tendo como objetivo "mobilizar a juventude para participar de forma ampla do processo de institucionalização das políticas culturais de seu município, discutindo uma perspectiva de gestão cultural que entende a cultura como um direito"; (3) "Sarau Afrobase", promovido por jovens de um núcleo de educação e cultura afro-brasileira localizado no bairro do Rio Pequeno, periferia da zona oeste de São Paulo, e que se propôs a compartilhar músicas, poesias, danças; ${ }^{9}$ (4) "Mostra de cultura Karajá Ixybiowá", que aconteceu no espaço Instalações, desenvolvendo "oficinas de pinturas corporais, mostra de artesanato, canto, dança e rituais, com o objetivo de valorizar e apresentar a cultura dos povos tradicionais"; (5) exibição do curta Redução da maioridade penal: você é contra ou a favor?, produzido por um grupo de estudantes do Colégio Estadual Polivalente de Itambé/BA; (6) exibição do documentário Doc cine Campinho: da terra à tela, sobre "uma ação cultural que ocorre desde 2007 na região de Guaianases" em São Paulo, e que pretendeu "discutir a juventude e violência na periferia e o acesso à cultura e ao lazer em bairros afastados dos grandes centros"; (7) "Mamapya Bahsamori Mahsa", que propôs apresentar "danças rituais do alto Rio Negro com o intuito de fortalecer e preservar a cultura indígena”. (BRASIL, 2015a)

A seguir, detalhamos os desafios para a realização da Manifesta, inclusive os que fizeram que dez atividades selecionadas não conseguissem se apresentar. Quanto à metodologia, cabe ainda destacar que, no credenciamento do evento, os participantes receberam um guia que continha a programação de cada espaço da mostra, bem como um resumo de cada uma das atividades.

9 Disponível em: http://bit.ly/2yaDn3j. Acesso em: 24 jul. 2019. 


\section{Desafios adminISTRativos e políticos}

Os maiores desafios para a realização da mostra estão relacionados às questões de infraestrutura e logística para um evento com 3 mil pessoas: desde um local adequado e disponível para a realização de atividades com todos os participantes e para trabalhos em grupos menores, até a emissão de 2.500 passagens em meio a uma greve de servidores do Serviço Federal de Processamento de Dados (Serpro), que inviabilizou o funcionamento do sistema de emissão de passagens da administração pública federal.

Por inexperiência dos organizadores, a definição do local e o encaminhamento do processo de licitação da empresa responsável por fornecer os materiais e serviços para o evento levou muito tempo. Dos poucos locais existentes em Brasília e disponíveis no período, a opção de realização no Estádio Nacional Mané Garrincha mostrou-se mais econômica do que a locação de um centro de convenções e eventos privado, entretanto, foi resolvida em data muito próxima à realização do evento, o que inviabilizou o planejamento e a organização prévia dos trabalhos de modo a antecipar possíveis problemas. Além disso, diante da inviabilização da emissão de passagens aéreas pelo sistema da administração pública federal, a contratação de uma empresa para o serviço também só foi conseguida em data próxima à realização do evento, o que gerou inúmeros problemas, como, por exemplo, a não participação de grupos selecionados. ${ }^{10}$

Quando a $3^{\text {a }}$ CNJ foi realizada, o processo do impeachment da presidente Dilma Rousseff havia sido recentemente aceito pelo então presidente da Câmara dos Deputados, Eduardo Cunha. A presidente Dilma aproveitou a ocasião para, em seu discurso de abertura da Conferência, reafirmar pautas fundamentais à democracia e à luta pelos direitos dos jovens, tais como: fortalecer e desenvolver

1021 proponentes de oito atividades selecionadas para a Manifesta não conseguiram participar por problemas com a emissão das passagens aéreas. 
a democracia; ampliar a participação direta da juventude; democratizar o acesso ao conhecimento, à informação, à cultura e à educação de qualidade, com oportunidades de trabalho decente aos jovens, com ações práticas a favor da sustentabilidade, com uma política de segurança que respeite os direitos dos cidadãos e favoreça a diversidade.

Vale ressaltar que diante da crise política e econômica que o país atravessava no final de 2015, o governo implementou uma reforma administrativa com cortes de gastos, ministérios, secretarias e cargos. A Secretaria Nacional de Juventude correu o risco de ser extinta, ainda que suas atribuições tenham sido incorporadas pelo novo ministério que juntou as pastas de política para mulheres, da igualdade racial e dos direitos humanos. Em seu discurso, a presidente Dilma garantiu que a SNJ ficaria e que o novo ministério passaria a se chamar Ministério das Mulheres, da Igualdade Racial, da Juventude e dos Direitos Humanos. Tal mudança - que, à primeira vista, pareceu subir o status de secretaria para ministério -, na prática, considerando os cortes e rearranjos dos governos seguintes, reduziu o quadro de servidores e a capacidade de gestão da SNJ.

O crítico e tenso contexto político somado aos problemas organizacionais da $3{ }^{\mathrm{a}} \mathrm{CNJ}$ - e, mais especificamente, os problemas com a falta de acordos claros com os responsáveis pelo Estádio Nacional Mané Garrincha, da Secretaria de Turismo do Distrito Federal - dificultaram a realização do evento, prejudicando seus participantes. Por indisposição da Secretaria de Turismo do Distrito Federal, o local do evento foi lacrado no primeiro dia (16 de dezembro de 2015), durante a realização do show de abertura do rapper Emicida, permanecendo assim até às $13 \mathrm{~h}$ do dia seguinte. ${ }^{11}$ A tensão para a finalização do show contou com a força da polícia. Além da ameaça de entrada da polícia para acabar com a festa - por parte dos

11 Estavam previstas duas horas de show, com participações especiais de Karol Conka, Drik Barbosa, Raphão Alaafin, Muzzike e Rico Dalasam, mas após quarenta minutos o show teve que ser encerrado. 
responsáveis pelo estádio -, houve repressão aos jovens que estavam do lado de fora do estádio e queriam entrar para ver o show. Desse modo, houve atraso em toda a programação do segundo dia da Conferência, além da exigência de que o evento finalizasse antes do previsto: a programação da Manifesta previa atividades até as 23h, entretanto, para a continuidade do evento, a administração do estádio exigiu o encerramento às $20 \mathrm{~h}$. Sendo assim, as atividades da Manifesta tiveram que, considerando os espaços e as condições estruturais disponíveis, reorganizar o tempo das apresentações, sem contar outras demandas que surgiram das tensões políticas existentes nos processos de participação social, com disputas de ideias e propostas. Nesse último caso, ressaltamos a necessidade de realização de plenárias gerais para a leitura do Regimento (BRASIL, 2015c) e para a abertura dos grupos de trabalho e esclarecimentos de sua metodologia. ${ }^{12}$ Além disso, essas plenárias foram realocadas no espaço de apresentações da Manifesta, o que também dificultou o cumprimento da programação planejada para esse espaço..$^{13}$

Outro desafio a ser considerado no sentido da aprendizagem com essa experiência foi a falta de integração da metodologia dos grupos de trabalho com as intervenções culturais da mostra. As atividades eram simultâneas, mas organizadas de modo a permitir percursos temáticos, através dos quais o participante poderia circular pelos espaços e participar tanto dos grupos de trabalho quanto das atividades da Mostra que trabalhavam com temas de seu interesse. Entretanto, ainda que a reorganização das atividades tenha procurado manter e comunicar os horários previstos das atividades, os percursos temáticos foram prejudicados.

12 A $3^{\mathrm{a}}$ Conferência Nacional de Juventude se organizou em grupos de trabalho para a reflexão e o debate em torno de onze eixos temáticos, sendo eles: Participação; Meio Ambiente; Segurança e Acesso à Justiça; Educação; Trabalho; Saúde; Cultura; Esporte; Diversidade; Comunicação; Território e Mobilidade.

13 Mesmo diante de adaptações e reduções no tempo das apresentações, o proponente de uma atividade de dança de Valença-BA e um grupo de teatro de Fortaleza-CE não conseguiram se apresentar. 


\section{Algumas Considerações e APREndizados}

Mesmo diante de inúmeras adversidades, a partir da vivência da Manifesta e de alguns relatos dos participantes é possível afirmar que a mostra cultural pôde contribuir para ampliar a participação da juventude no processo democrático estimulado pela $3^{\mathrm{a}} \mathrm{CNJ}$, inserindo novos atores nesse contexto. Além disso, mostrou o rico potencial criativo de jovens de diversos cantos do país, que compartilharam suas produções e possibilitaram momentos de interação e aprendizado, complexificando a dimensão política predominante. Segundo a jovem Terená, do Ponto de Cultura Afrobase da cidade de São Paulo, em entrevista concedida durante a $3^{\text {a }}$ CNJ:

A Manifesta foi uma ideia muito boa. Eu já participei de vários encontros de estudantes e nunca vi isso. [...] A gente foi vetado de falar por muito tempo, o povo preto, as mulheres foram por muito tempo impedidas de falar. Então agora a gente tem que aproveitar e falar mesmo. Pegar os microfones, cantar, batucar, dançar, fazer o que representa a gente, fazer o que faz a gente feliz. E até por isso que eu acho importante a Manifesta. Que a gente teve shows grandes aqui também, mas o mais importante num evento de juventude é mostrar o que a juventude está fazendo. O que a juventude periférica, a juventude que é sempre excluída está fazendo. (SARAU..., 2015)

Considerando os objetivos das atividades da Mostra Cultural, jovens ciganas apresentaram suas danças, músicas e crenças com o intuito de quebrar preconceitos e estigmas. Jovens indígenas realizaram danças, rituais, cantos, pinturas corporais, produziram e mostraram artesanatos, com o objetivo de fortalecer sua cultura e a luta para garantir seus direitos e territórios. Jovens drags e queers intervieram desconstruindo normativas, fortalecendo o universo das pessoas transgênero e visibilizando as violências machistas e 
misóginas, físicas ou simbólicas. Jovens comunicadores independentes compartilharam suas produções e atuações para a democratização dos meios de comunicação, confrontando e disputando narrativas. ${ }^{14} \mathrm{~A}$ juventude camponesa compartilhou suas experiências e desafios, buscando fortalecer o processo da reforma agrária popular. Em suas intervenções e manifestações poéticas, os jovens pautaram a luta contra o racismo, a intolerância religiosa, a violência policial e o extermínio da juventude negra, refletindo sobre o papel do Estado e dos movimentos sociais na construção de uma sociedade mais justa, solidária e ativa quanto às questões socioculturais e ambientais.

Considerando a simultaneidade das atividades e o desafio da falta de integração dos Grupos de Trabalho com as iniciativas da mostra, uma questão que se abre - e que, por ter nos ocorrido posteriormente ao processo da $3^{\mathrm{a}} \mathrm{CNJ}$, não foi acompanhada metodologicamente no decorrer dessa experiência - é entender de que forma tais iniciativas culturais incidiram nas diretrizes que pautam a construção de políticas públicas. Em outras palavras, como a dimensão cultural da Conferência se cruzou com a deliberação discursiva?

Ao final de quatro dias de encontros, foram definidas onze prioridades de políticas públicas para a juventude (uma por eixo temático dos grupos de trabalho) e três prioridades gerais, sendo elas: i) não à redução da maioridade penal e, sim, ao cumprimento efetivo das medidas do Estatuto da Criança e do Adolescente (ECA); ii) ampliar e acelerar o processo de reforma agrária e regularização fundiária, bem como o reconhecimento e a demarcação de terras de povos e comunidades tradicionais; iii) garantir a implantação do Sistema Nacional de Juventude.

Naquele momento, cabia-nos pensar em como garantir o comprometimento dos entes públicos com o que fora deliberado na

14 Cabe ressaltar que alguns coletivos de comunicação participantes da mostra realizaram a cobertura colaborativa da Conferência, vide: http://juventude.gov.br/conferencia/noticias/participacao-de-coletivos-de-comunicacao-marcou-a-cobertura-colaborativa-da-3confjuv 
Conferência, para avançar na realização das demandas apresentadas pela sociedade. Ou ainda, em como garantir a continuidade do diálogo entre o poder público e os cidadãos para além do momento das Conferências. Mais especificamente, considerando o aprimoramento dos processos de participação social, em como o experimento da Manifesta poderia se tornar uma referência para reconhecer e potencializar as várias formas de expressão da sociedade brasileira. Agora, estamos diante de um contexto de ascensão de formas conservadoras e autoritárias de atuação do Estado, que rompem com as conquistas democráticas, tirando do horizonte de possibilidades o desenvolvimento dos mecanismos de participação popular em que a experiência da Manifesta pôde se realizar.

No ano em que o governo deveria estar promovendo a $4^{\text {a }} \mathrm{CNJ}$ e apresentando os avanços em relação às demandas propostas pela sociedade, em direção oposta ao que foi deliberado na $3^{\text {a }} \mathrm{CNJ}$, o presidente Bolsonaro, em live nas redes sociais no dia 4 de julho de 2019, afrontou o ECA, a Constituição brasileira e as Convenções da Organização Internacional do Trabalho, ao estimular o trabalho infantil. Outra ação em direção oposta ao que foi deliberado pela juventude é sua intenção declarada de não demarcar nenhuma nova terra indígena, por meio da Medida Provisória ${ }^{\circ} 886$, editada no dia 19 de junho de 2019, que transfere a responsabilidade sobre a demarcação das terras indígenas da Fundação Nacional do Índio (Funai) para o Ministério da Agricultura. Uma medida inconstitucional, uma vez que o assunto já havia sido proposto pelo governo, tratado e recusado pelo Congresso Nacional.

Entendemos a democracia como única forma política capaz de reafirmar os princípios humanistas e as lutas contra as formas de dominação e desigualdade. Ao contrário do que o atual governo alimenta com os cortes e o desmantelamento das políticas públicas, em uma sociedade democrática, a cidadania, a educação e a cultura são fundamentais para o desenvolvimento do indivíduo e da 
sociedade. Cabe lembrar que resiste em nossa história social a luta para aprofundar e aprimorar os mecanismos democráticos.

\section{ReferÊNCIAS}

$3^{\text {a }}$ CONFERÊNCIA Nacional da Juventude. Secretaria Nacional de Juventude. Brasília, DF: Secretaria Nacional de Juventude, [2019]. Disponível em: https://bit.ly/2OwzPAm. Acesso em: 9 jul. 2019.

AVRITZER, Leonardo. A qualidade da democracia e a questão da efetividade da participação: mapeando do debate. In: PIRES, Roberto Rocha (org.). Efetividade das instituições participativas no Brasil: estratégias de avaliação. Brasília, DF: Ipea, 2011. p. 13-25.

BRASIL. Presidência da República. Constituição da República Federativa do Brasil de 1988. Brasília, DF: Presidência da República, 1988. Disponível em: http://bit.ly/2SB98Mq. Acesso em: 5 jul. 2019.

BRASIL. Lei ${ }^{\circ} 12.852$, de 5 de agosto de 2013. Institui o Estatuto da Juventude e dispõe sobre os direitos dos jovens, os princípios e diretrizes das políticas públicas de juventude e o Sistema Nacional de Juventude SINAJUVE. Brasília, DF: Presidência da República, 2013. Disponível em: https://bit.ly/1chz4UQ. Acesso em: 24 out. 2019.

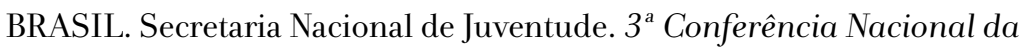
Juventude: guia do participante: etapa nacional. Brasília, DF: SNJ, 2015a. Disponível em: https://bit.ly/2PhfZey. Acesso em: 24 out. 2019.

BRASIL. Secretaria Nacional de Juventude. Chamada Pública $n^{\circ}$ 01/2015 SNJ/SG/PR. Brasília, DF: SNJ, 2015b. Disponível em: http://bit.ly/2Y2x15I. Acesso em: 3 jul. 2019.

BRASIL. Secretaria Nacional de Juventude. Regimento da $3^{a}$ Conferência Nacional de Juventude. Brasília, DF: SNJ, 2015c. Disponível em: http://bit.ly/2Y2yF7o. Acesso em: 3 jul. 2019.

BRASIL. Secretaria Nacional de Juventude. Resolução 08/2015, da Comissão Organizadora Nacional. Brasília, DF: SNJ, 2015d. Disponível em: http://bit.ly/30RVurd. Acesso em: 3 jul. 2019.

CHAUI, Marilena. A nova classe trabalhadora brasileira e a ascensão do conservadorismo. In: JINKINGS, Ivana; DORIA, Kim; CLETO, Murilo (org.). Por que gritamos golpe? Para entender o impeachment e a crise política no Brasil. São Paulo: Boitempo, 2016. p. 16-21. 
KLEIN, Naomi. A doutrina do choque: a ascensão do capitalismo de desastre. Tradução de Vania Cury. Rio de Janeiro: Nova Fronteira, 2008.

MAZUI, Guilherme. Bolsonaro empossa Abraham Weintraub como novo ministro da Educação. G1, Brasília, DF, 9 abr. 2019. Disponível em: https://glo.bo/2Z8zckp. Acesso em: 8 jul. 2019.

MIGUEL, Luis Felipe. A democracia na encruzilhada. In: JINKINGS, Ivana; DORIA, Kim; CLETO, Murilo (org.). Por que gritamos golpe? Para entender o impeachment e a crise política no Brasil. São Paulo: Boitempo, 2016. p. 29-33.

ONU. Declaração Universal dos Direitos Humanos. Rio de Janeiro: UNIC Rio, 2009. Disponível em: https://bit.ly/2APIx5U. Acesso em: 24 out. 2019.

SANTOS, Boaventura de Souza; AVRITZER, Leonardo. Introdução: para ampliar o cânone democrático. In: SANTOS, Boaventura de Souza (org.). Democratizar a democracia: os caminhos da democracia participativa.

3. ed. Rio de Janeiro: Civilização Brasileira, 2005. p. 39-82.

SARAU Afrobase - \#ConfJuv. Brasília, DF: SNJ, 2015. 1 vídeo (2 min). Publicado pelo canal SNJuventude. Disponível em: http://bit.ly/2yaDn3j. Acesso em: 24 jul. 2019.

SZWAKO, José. Participar vale a pena, mas...: a democracia participativa brasileira vista pelas lentes da utopia. In: SOUTO, Anna Luiza Salles; PAZ, Rosangela Dias Oliveira da (org.). Novas lentes sobre a participação: utopias, agendas e desafios. São Paulo: Instituto Pólis, 2012 .

UNESCO. Edital 002 - Perfil 01: Termo de Referência. Brasília, DF: Unesco, 2015.

WILLIAMS, Raymond. Culture is ordinary. In: WILLIAMS, Raymond. Resources of hope: culture, democracy, socialism. London: Verso, 1989. p. 3-14.

WILLIAMS, Raymond. Base e superestrutura na teoria da cultura marxista. In: WILLIAMS, Raymond. Cultura e materialismo. Tradução de André Glaser. São Paulo: Ed. Unesp, 2011. p. 41-68. 